INTERNATIONAL BULLETIN OF BACTERIOLOGICAL NOMENCLATURE AND TAXONOMY

Vol. 15, No. 1 January 15,1965

pp. $25-32$

\title{
A FOCUS ON THE MEANING OF BACTERIAL SPECIES
}

\author{
R. E. Buchanan \\ Department of Bacteriology \\ Iowa State University \\ Ames, Iowa
}

SUMMARY. The significance of the term "individual" as applied to the definition of the taxon "species" is reviewed. For clarity in classification and nomenclature in bacteriology it is urged that (1) for each genus there should be definite designation of a type species, (2) for each species there should be recognition eithe $r$ of a type strain or of a neotype strain. These should be accessible in true type culture collections for distribution and use. For each type or neotype strain there should be available a reasonably complete description which may be emended as new techniques of differentiation are developed and applied. The concept of type and neotype in many cases should be carried to the level of subspecies and not infrequently to infrasubspecific forms, including strains usefulin diagnosis in chemical studies, serotypes, variants and strains useful in industry.

Current literature in bacteriology reveals much protest concerning the inadequacy of the definition of the taxon "species." There is often the implicit assumption that for some ill-defined reason the phrase "species of bacteria" does not connote quite the same concept as does "species" in other areas of biology, such as botany and zoology. The reasons for this current assumption need to be explored and, if possible, a workable definition of "species" in bacteria developed.

Bacteriology differs from the other two biological disciplines, botany and zoology, in some of its basic approaches to taxonomy, particularly those significant in classification. 
Differences and likenesses based upon physiological characters so prominent in systematic bacteriology are little emphasized by botanists and zoologists. Botanists who deal with vascular plants and zoologists who study the nonmicroscopic forms of animals rarely emphasize physiology or physiological characters in their descriptions of species. Occasionally there is included some reference to habitat. Irritability, taxes, movement, or other physiological characteristics, are noted. No specific requirement that species of animals and plants must be delineated exclusively by the use of morphology is to be found in either the botanical or zoological codes of nomenclature.

To make systematic bacteriology more definitely scientific, to put in order our ideas as to the meaning of each of the four categories or levels of taxa, most important in classification, we need further to define, insofar as is possible, what constitutes the correct nomenclature for these taxa when defined. In other words, we should formulate practical and useful concepts of the meaning of genus, species, subspecies and infrasubspecific forms.

Fundamentally, in all three biological disciplines, the ultimate unit in taxonomy is the individual, though the basic unit is the species. The meaning of individual requires some consideration. The International Code of Nomenclature of the Bacteria and Viruses (Principle 7) states:

"Every individual is treated as belonging to a number of categories of consecutive rank and consecutively subordinate. Of these the species is the basic one."

Somewhat similar definitions are to be found also in other nomenclatural codes.

The development of a workable definition of a bacterial species necessitates consideration of whether in systematic bacteriology this elementary taxon, the individual, can be as readily defined as in most areas in botany and zoology. We find upon analysis that the query, "What is an individual?" among the bacteria is rather more complex than might be anticipated. From a practical, and also from a scientific, point of view, there are several definitions or concepts of the taxon "individual" apparently made necessary by differences in bacterial morphology. Particularly noteworthy is the fact that in general classification of bacteria is based 
upon populations as well as upon morphology of individuals. Living cultures rather than herbarium or museum material are essential.

The following include the more important assumptions made in current literature as to the meaning of the term "individual" in bacteriology:

1. An individual is a single bacterial cell, usually, but not invariably, separated from other similar cells and functioning quite independently of other similar cells. This seems to be the definition assumed when emphasis is upon cellular morphology.

2. An individual is the organism which develops from a single spore or reproductive body, which develops branched hyphae and a mycelium wherein the cells remain united during vegetative growth. The individual, in this case, may be either multicellular or coenocytic. This is the individual usually assumed when dealing with organisms such as those found in the genus Streptomyces.

3. An individual consists of a chain of cells which remain united during vegetative growth, forming a filament (sometimes rather unfortunately designated a trichome), in some cases with morphological differentiation among the cells, such as the development of the basal cell as a holdfast. Here one may regard the filament as the individual in such genera as Crenothrix.

4. An individual is a population resulting from the multiplication of a single cell or groups of cells. This population shows independent metabolism but coordinated motion and striking cooperation in the formation of fruiting bodies (myxangia). Here belong the true myxobacters.

5. An individual from a practical point of view is a pure culture of a microorganism. Perhaps better it should be defined as a strain which is perpetuated in pure culture. It may be a pure culture of numbers 2,3 , and 4 defined above. 
It may be noted that some of the above definitions do some violence to the root meaning of "individual," i. e., something that cannot be resolved into lower viable units.

There are two approaches to the determination of "relationship" among microorganisms. One is that of ancestry, that is, of phylogeny, in which individuals (pure culture) are placed together in a species if they have the same immediate ancestry. Microorganisms apparently closely resembling each other may be isolated from different habitats, perhaps one in Europe and the other in Australia. We cannot assume that they have any immediate common ancestry, however much they are alike. We know from fossil remains that bacteria were associated with fossil animals and plants. We may make some conjectures as to general relationships to present living forms on the basis of morphology of the fossil remains and, in some cases, evidences of the kinds of changes which they produced in their environments.

The alternative to classification by phylogeny usually employed is to assume that relationship between individuals can be determined by critical evaluation of resemblances and differences, with no definite statement that such relationship is phylogenetic rather than phenetic.

A widely accepted definition of species, utilizing the criteria of like and unlike, is one proposed by Mayr. It reads:

"Species are groups of actually or potentially interbreeding populations which are reproductively isolated from other such groups."

Has Mayr's definition application to the circumscription of bacterial species? The discovery in recent years that certain bacteria, at least, have one or more mechanisms which make possible the transfer of genes from one cell to another has resulted in a rash of attempts to use the interbreeding definition just given in definition of bacterial species. One must recognize, however, that Mayr's definition of interbreeding as applied in zoology implies the existence of two sexes and of true sexual reproduction. As commonly recognized in higher plants and animals, true sexual reproduction involves meiosis. The parasexual passage of genes of bacteria does not involve meiosis, hence is not strictly interbreeding. This type of gene transfer will undoubtedly have 


\section{AND TAXONOMY}

significance in bacterial taxonomy, but just how it may be used has not as yet been adequately demonstrated in practice. Simpson has stated quite clearly with reference to the definition of species quoted above that "the taxonomist can apply it with little difficulty to at least nine-tenths, perhaps even more, of the animals to be classified," but he warns, "it does not apply even in principle to temporarily sequential species or to species of uniparental organisms." He notes for special, but very common, cases the "genetical definition is simply irrelevant" and, again, "it remains true that there are obligate uniparental organisms, including some animals that must be classified. It is further true that students of those animals recognize among them groups that seem to be the same sort of things as species in biparental animals, and they are also called species and named as such. They obviously cannot be genetical species by the accepted definition, and in fact Dobzhansky (1937) has insisted that there cannot be a species category for uniparental organisms." Simpson characterized the Dobzhansky conclusion as a misapprehension and insists that the re should be recognized "an evolutionary species category... that is fully congruent with the genetical (biparental) species." Ravin (1960) gives a masterly summary of the problem in Bacteriological Reviews.

If species of bacteria are to be recognized, and it is assumed that this is essential, we can rely only in very limited fashion on phylogeny. In spite of certain glowing preliminary advertising nothing has yet appeared that profoundly effects bacterial taxonomy.

It seems that we must still use the species concept, "A species is a group of related individuals." Obviously utilitarianism requires that we assess relationships on the basis of resemblances and differences.

In biological taxonomy, it has long been recognized that the selection of one individual or specimen (the so-called type specimen) in each species with which comparison of other individuals could be made was not only desirable but imperative. The nomenclatural codes of all three biological disciplines agree that the type method involves direct comparison of the specimen being investigated with the type specimen. Theoretically, at least, a species can therefore be defined as including all individuals sufficiently closely related to the type specimen. Herbaria, museums, insect 
collections and, we may hope, microbiological type culture collections, are the repositories of tens of thousands of types useful in identification of specimens and for the justification of recognition of new species. The use of the type concept in bacteriology was first applied to the taxonomy of genera. That genera of bacteria could be most helpfully defined by the designation of a type species for each genus was recognized during the first decade of the 20 th century. One group which emphasized the importance of such designation was the Committee on Taxonomy of the Society of American Bacteriologists. This committee and its several members designated the type species for many of the better-known genera of bacteria. In short, a genus in bacteriology may, from a practical point of view, be defined as including its type species together with the species deemed sufficiently closely related on the basis of resemblances and differences to be included in the genus. But the task of defining the bacterial taxa by means of typification has lagged far behind the progress in the other two biological disciplines, botany and zoology.

The reason for this unfortunate lag is quite clear. The type specimen of the species of one of the higher plants, of insects, of most animals, can be kept in satisfactory shape for comparison either by drying or by use of appropriate preservatives. This is sometimes, but rarely, true of the bacteria. Certain of the species of the order Myxobacterales produce relatively large fruiting bodies (myxangia) which may be dried and preserved indefinitely. The specimens prepared by Dr. Thaxter of Harvard over 60 years ago are still usable, and, in some cases, have been designated as type specimens. But this kind of a type specimen is the rare exception. Dried specimens of most bacteria are practically useless as types of species.

In general, it seems that the only practicable type specimen for most bacteria is a pure culture, which may be maintained indefinitely without significant change in its characters. It may often be lyophilized and, when used for comparison, may again be grown in suitable culture media. In practice, then, in bacteriology in most cases the type specimen of a species is a living culture of a strain.

A living culture is one which is growing or which is capable of growth. Subcultures from the type culture can be made indefinitely, a type culture can be multiplied. While 
there are some inherent difficulties, a great advantage in bacteriology is that the type can be replicated and widely distributed. Anyone wishing to study the type can do so without difficulty once it has been designated and preserved.

Technically, one can scarcely designate each of the replicated cultures from the original type culture as themselves type cultures. The appropriate terminology might perhaps be "a subculture of the type strain of the Bacillus subtilis."

Kral, in the latter part of the 19 th century and the first decade of the 20 th century, attempted to bring together pure cultures of named organisms from various laboratories and act in his laboratory in Prague as a center for their distribution. Culture collections were later maintained in many universities and bacteriological laboratories. Important culture collections such as those of the fungi and bacteria of the order Actinomycetales at Baarn in the Netherlands, that of the Lister Institute in London, and the American Type Culture Collection in Washington came into existence. In some cases they were named Type Culture Collection though in relatively few instances have all the cultures (strains) maintained and distributed been strictly eligible for the designation type strains or type cultures. In recent years, however, the tendency to emphasize the maintenance of true type and neotype cultures has been emphasized. A type culture collection without true type strains is like a Bureau of Standards without standards. The need is now well recognized.

Theoretically, we should be able to define each species of bacteria by an adequate and complete description of the type strain with the added notation of the differences to be found in other strains believed to be sufficiently closely related. The species, in other words, must include not only the type strain but also closely related strains.

The great drawback to the use of this definition of a species is that the species boundaries must always be determined subjectively by the taxonomist concerned. Actually the judgments of the qualified taxonomists in species delimitation have proved to be surprisingly good. The inescapable fact is that decisions as to the allocations, however much the taxonomist wishes to be objective, are in reality subjective. Is it possible to make the decision as to relationship on the basis of greater objectivity? The current interest in numerical taxonomy seems likely to bring at least a part of the answer. 
Dr. Sneath and his coworkers seem to have opened up some distinctively promising leads. Workers in botany and zoology and many in bacteriology have been, directly or indirectly, exploring the so-called neo-Adansonian approach to the assessing of relationships. If one defines a species in bacteriology as a type strain together with other strains sufficiently closely related it seems evident that by the correct array of characters for comparison it is possible to get a numerical expression of the degree of all interrelationships. In other words, a taxonomist faced with the problem of determining somewhat less arbitrarily "closeness of relationship" (whether a particular strain belongs in a particular species) should with more objectivity be able to delimit the species.

In many cases the identification of a type strain for a species of bacteria whose names are in current use is impossible. For such it is highly desirable, under the rules of the code concerning international cooperation in such matters, that there be immediate designation of neotypes of species. Type strains or neotype strains of subspecies and of important so-called infrasubspecific forms are frequently advisable. In some cases mutants of species have been found useful in the making of chemical determinations and the identification, naming and preservation of such cultures as types would seem to be imperative. Significant use of bacterial types and neotypes should be visualized as goals to be used in the monographic treatment of any group of bacteria. 